\title{
Confronto Essencial entre Heiddeger e Hegel
}

\author{
Irineu Strenger \\ Professor Titular de Direito Internacional \\ Privado da Faculdade de Direito da \\ Universidade de São Paulo.
}

Uma análise filosófica que, como a presente, nasce de intenção puramente sistemática, difere de estudo histórico no sentido de que se preocupa apenas com a solução objetiva de configuração de problemas e não com exposição e comparação exaustivas de determinadas filosofias como "cosmovisão" (Weltanschauungen) ou "sistemas de de pensamentos". As tarefas prementes impostas, hoje em dia, à filosofia diante de humanidade que, mergulhada em angústia e confusão desabrocha para nova maturidade e "Gestaltwerdung", e que já encontra esporadicamente simpatia intensa, exigem cada vez mais solução abrangente do problema da posição do ser humano - não em um "cosmos" inicialmente problemático e duvidoso, mas no ponto de interseç̧ão das definições de verdade que o dominam e que são decisivas para o modo de vivência existencial.

Se o ser humano foi chamado de "junco oscilante", mas igualmente pensante, é preciso acrescentar que o centro desse raciocínio cria o ponto de partida decisivo para seu modo de vacilar, para sua agitação na tormenta existencial, pois é nele que esse "junco oscilante" se fixa ao solo arraigado da existência. Esse centro é o logos representando a verdade da existência, como esta se concentra no interior do ser humano, provocando a evolução existencial de sua personalidade. Esse centro é a intersecção dos objetivos existenciais, que formulamos como antagonismo e contradição e confrontamos na forma de dois pensadores. Portanto, do ponto de vista da origem, os problemas relacionados são do tipo antropológico se refletirmos que, por um lado, na essência da verdade, sua concentração se encontra dentro do ser humano, enquanto, por outro lado, o conceito de todas as formas de expressão do ser humano concreto devem ter sua fonte de origem nessa concentração. A relação entre logos e antropos é relação muito íntima, que permite determinar o ser a partir de algo como consciência e in-consciência, assim como qualquer tipo de desmistificação dentro de suas possibilidades e limitações.

Nesse contexto, conceitos como "antagonismo" e "contradição" não deverão prevalecer como princípios rígidos, mas puramente como 
sutilezas de polaridade. Em nossa análise formam os pontos cruciais da explicação de cujo âmago pode se realizar um confronto. A força lógica de Hegel, protunda e abrangente, e o fluir perpétuo, incansável e insistente, de Heidegger, não poderiam ser captados de modo algum em tais princípios. Us momentos acima citados, no entanto, devem caracterizar a diferença existente entre os dois pensadores. A essência neles contida só poderá demonstrar-se no decurso de nosso confronto, sendo necessário deixar qualquer definição "a priori" de lado, para evitar equívocos. A comparação em si não pode ser de forma alguma superficial, realizada entre quaisquer momentos dados, existentes, quando gerada a partir do próprio pensamento vivo. Onde se trata do pensamento nas formas de sua realização, a igualdade de uma comparação - o centro da relação — só pode ser o próprio pensamento, pois é o mesmo que se manifesta em suas expressões. Na hipótese de tal comparação é importante, sobretudo, confrontar não momentos heterogêneos, mas sim comparar os análogos correspondentes, como os relacionados, entre si, para que em sua diferença possam destacar-se com absoluta pureza. Pureza de conceito é um dos deveres primordiais impostos à filosofia nos tempos atuais, para que o emaranhado de línguas da nossa época, que suga em seu turbilhão todos os sentimentos humanos, possa alcançar clareza nos elementos autênticos de sua catarse.

Os dois pensadores, sobre os quais se fundamenta o nosso estudo, do ponto de vista das definições formuladas como contradição e antagonismo, não foram escolhidos com base em uma perspectiva histórica ocasional, mas por necessidade objetiva. Ambos os filósofos na área de tensão de sua polaridade representam o manancial vivo de todas as tendências fecundas e estímulos futuros da filosofia, desenvolvendo a acuidade da problemática concludente, exigindo para o seu domínio, o máximo de forças. No que diz respeito a filósofos realmente eminentes, o mundo demonstra tendência fundamental em seu próprio caráter e na exclusividade desses pensadores de proselitismo (tese) e antagonismo (antitese), extremos que não correspondem à coisa em si, mas representam necessidade única que a protege. Essa ingenuidade de duas faces proporciona o meio, permite à causa do espírito mais forte prosperar, repelindo a vaidade de um sabe-tudo imaturo.

A filosofia, porém, não se realiza nos recônditos enclausurados do espírito, e sim na lei de abnegação que penetra todo concreto. Comparação é, portanto, método para romper esses espaços e mostrar novamente a grandeza e as limitações de dois filósofos identificados um ao outro, fazendo com que toda a problemática consolidada seja posta em vibração a partir de outro centro. Como lei de tal dialética podemos afirmar "a priori", que a maneira como esses filósofos comparados interpretam ou teriam interpretado um ao outro, forçosamente terá vacilações. $\mathrm{E}$ isto porque essa interpretação mútua é gerado do ponto de vista de seus modos de pensar e não de seus interiores, o que forçosamente provoca alteração de perspectiva. Em 
nosso caso será dada ênfase à crítica da interpretação heideggeriana de Hegel, já que o contrário só poderia ser suposto. Além disso, crítica imanente à filosofia de Hegel provará ter sido fecundada por Heidegger, enquanto a tentativa de evolução crítica de motivos heideggerianos poderia ser, em parte, inspirada por Hegel. Todavia, o que se pretende realizar neste caso é tudo menos combinação superficial de modos de pensar heterogêneos; o que se pretende tentar na tensão mútua dessas duas maneiras, que na verdade são modos do pensar, é criar lugar de fecundação de novas manifestações de pensamento.

Parece que Heidegger não baseou sua doutrina inicialmente em argumentação direta com Hegel. A princípio a doutrina de Heidegger sofreu influência, em primeiro plano, do neokantismo e do próprio Kant, da escolástica e Aristóteles, de Agostinho, Descartes e Pascal, aos quais se juntou o impulso poderoso de Husserl. É certo, porém, que o filósofo já desde muito cedo assimilara a doutrina de Hegel, conforme pode ser depreendido da conclusão de seu trabalho de doutorado, principalmente pela característica alemã da "Geisteswissenschaft" (ciência do espírito) que difere de forma acentuada da tradição holandesa, inglesa e italiana, quase não levando em consideração a ciência da lógica. Através de muitos vultos da filosofia que vieram depois de Hegel, e que absorviam unilateralmente os motivos principais do último grande lógico e metafísico e que, como Dilthey, os usavam para fecundar ciências individuais ou que, como Marx, Nietzsche e Kierkegaard, representavam parcialmente preocupação essencial com relação a Hegel. Sem no entanto poder transformá-la para a forma pura da verdade, Heidegger também indiretamente dialogava constantemente com Hegel. Todos estes motivos e interesses, ele os acolheu, contudo não em uma "síntese" superficial e impotente, mas induzido por emoção genuína, provocada pela angústia do tempo em razão de profunda penetração no âmago da filosofia ocidental em geral. Essa doutrina, todavia, não se desenvolve primariamente em oposição a Hegel, mas sim impulsionada por desejo interior de uma "Gestalt" (forma) própria; e é exatamente por esse motivo, ainda em parte oculto, que se relaciona profundamente àquela. Acreditamos, pois, que quando Heidegger se refere explicitamente a Hegel, a diferença não se manifesta evidentemente, porque justamente também no espírito de sua doutrina essa relação tinha de permanecer oculta. O próprio filósofo sugere isto quando, referindo-se à sua interpretação da crítica da razão pura, que difere da dos grandes filósofos idealistas, afirma: "Será que existe porventura no nosso próprio esforço, se é que podemos compará-lo, uma fuga oculta de algo que nós - e não só por acaso - não vemos mais?" (grifo nosso).

Heidegger insere a doutrina hegeliana na esfera da manifestação da verdade, que denomina de "a metafísica" e que vivencia como "época" excepcional da verdade existencial. A metafísica pensa nos níveis de seu desdobramento, o existir como a existência do ser, ou a existência como o ser, segundo a palavra de Aristóteles, mas não 
leva em consideração o que se oculta justamente no que foi pensado; na verdade oculta em seu agir até este se-ocultar, de modo a se tornar invisível a seus olhos. $O$ processo de grau em grau, de forma em forma, é a crescente autopenetração e autoconsolidação dessa manifestação que se realiza em apresentação da essência fundamentada no sujeito até que este sujeito, na certeza de sua subjetividade, tenha captado a essência em seu todo e tenha obliterado com o ser, assim imaginado, o horizonte do ser por completo. Mas, então, também é chegado o momento de enfrentar a época como época ou privação do ser em sua verdade e afirmá-lo, a fim de que o esconder-se do oculto se torne visivel preparando percepção mais profunda.

$O$ conceito de metafísica, refletido em profundidade e generosamente desdobrado corresponde à dimensão de sua realização; deixa porém outras zonas inexploradas e reúne, num ponto de vista, o que comumente é incompatível. Nietzsche, por exemplo, como seu último executor ao menos na qualidade de metafísico, poderia ter sido absorvido inteiramente por esse processo, mas não refere dimensões essenciais da doutrina hegeliana. O próprio Hegel combateu acirradamente a manifestação e o pensamento racional concretizante, também na forma do idealismo transcendental de cunho hantiano e fichteniano, que ele próprio denominou de subjetivo. Assim toda sua lógica deve ser considerada como a evolução do ser em sua verdade. Apesar de tudo Hegel é atingido de certa forma pelo conceito heideggeriano, quando este sofre modificação, segundo tentaremos demonstrar no decorrer do estudo. $\tilde{E}$, porém, igualmente, nossa tarefa livrar Hege] da interpretação de Heidegger, aprofundando e alargando concomitantemente a substância da metafísica e consequientemente transformando a posição de Heidegger.

O caminho traçado nos levará de uma consideração do método, essencial a qualquer filosofia genuína, ao problema da verdade, para então compreender a verdade em sua essência como temporalidade e a diferença de natureza e espírito como diferença existencial, surgida desta temporalidade, mas sempre com a preocupação de identificar os conceitos análogos dos dois filósofos em confronto essencial. Em sua essência sistemática essa evolução de conceito termina finalmente na esfera de problemas de uma filosofia de centro.

Diferença fundamental entre a filosofia e as ciências individuais consiste no fato de que para a filosofia o método não é apenas meio empregado exteriormente entre ela e o objeto, mas sim parte integrante dela própria, elemento essencial, que na evolução dessa ciência pura deve-se destacar como verdade mais profunda.

A diferença, no entanto, perde rigor à medida que as ciências individuais evoluem, aprofundando-se tanto em seu problema, como penetrando em si próprias. Na física atual, por exemplo, o método está tão intimamente ligado ao progresso e à revelação de seus temas que uma conscientização permanente da relação entre método e objeto 
torna-se imprescindível à evolução da própria ciência. Na verdade a ciência individual não consegue realizar este tipo de reflexão, enquanto se limitar apenas a si própria, deixando de tırar força de uma contemplação lógica. Ivias para a tilosotiia, que tem como objeto a verdade global, a evolução do metodo no todo, lado a lado com reflexão isolada, e seu elemento intrínseco: o método não é apenas a verdade aplicada externamente; em sua realização mais pura precisa revelar-se como a própria verdade.

Isto se aplica principalmente aos dois filósofos dos quais trata o presente estudo. ivIas, quanto mais o método ganhar em importância, tanto mais premente se tornará a tarefa de dedicar-lhe atenção à luz de reflexão crítico-sistemática. No caso de Heidegger tarefa desse porte contra dificuldades muito maiores do que com relação a $\mathrm{Hegel}$. Não somente, no caso deste último, o método se revela de forma concreta nos diferentes ramos da ciência filosófica, como também se apresenta particularmente desenvolvido na ciência da lógica, representado em toda sua pureza. Em contraposição, na doutrina heideggeriana, que se manifesta em um constante devir, o método ou o caminho não pode, a princípio, se tornar visível de forma tão inequívoca, o que o próprio filósofo exprimiu com a expressão "Holzweg".

Se o método filosófico está tão intimamente entrelaçado com a essência da coisa em si, como demos a entender, então é preciso que juntamente com a evolução criativa dessa coisa, o método também penetre na pureza de sua própria essência. Finalmente a relação assim expressa, entre coisa e método não pode ser externa nem quanto à coisa, nem quanto ao método. Segundo Hegel, conforme ainda teremos ocasião de pormenorizar, essa relação seria de tal forma, que a coisa ou a essência e o método se confundiriam, mas não no sentido de simples uniformidade, e sim de modo que a forma se transforme no momento da essência e a essência se apresente como momento da forma em ambos, acabando nessa transformação por convergirem.

Se pois na doutrina heideggeriana a coisa se manifesta de modo diferente do que na hegeliana - conforme presumimos e mesmo se considerarmos que esses modos, sendo modos da mesma coisa, devem estar em relação essencial um com o outro - então não somente o método, mas também a relação de mêtodo e coisa será, conseqüentemente, outra. Sempre quando temos de lidar com doutrinas filosóficas é inevitável que essa relação seja manifestada no nível mais elevado de seu desdobramento, tanto na essência do método como na essência da coisa em si. A coisa em si, porém, é, para os nossos dois filósofos, como será revelado, a existência em sua verdade. A comparação que toma como ponto de partida o método, tende, através do próprio método, alcançar a coisa em si, que se revela como centro único nos seus dois modos.

O método de Heidegger se apresenta de início como fenômeno-lógico, mas o que explica sobre isso no começo do "Sein und Zeit" 
não passa de um "preconceito preliminar introdutório", um preconceito, que tem de se afirmar antes de tudo na penetração concreta da coisa e somente revelar-se verdade como "idéia da fenomenologia", onde a "problemática central" "do sentido da existência" e da correlação entre existência e verdade é desenvolvida. A respectiva terceira parte correspondente do "Sein und Zeit" intitulada "Zeit und Sein" não foi publicada, de modo que dependemos, com relação a esse desenvolvimento, de manuscritos menores posteriores.

Na parte publicada de "Sein und Zeit", porém o método se afirma na revelação da existência, como do ser exemplar, em cuja realização existencial, ao mesmo tempo meio, a verdade do próprio ser deve se tornar visível. $O$ método se afirma dando à própria existência a possibilidade da exploração original e permitindo ao mesmo tempo sua própria interpretação. Heiddeger acompanha essa descoberta apenas para elevar existencialmente a essência fenomenal do conceito do explorado. Nessa particularidade não se diferencia em nada de Hegel, muito pelo contrário, percebemos profunda concordância quando pretende que a percepção se esforce para renunciar à liberdacie do conteúdo e "ao invés de representar o princípio arbitrário vivo do conteúdo, absorve essa liberdade e permite pela sua própria natureza, deixar-se levar contemplando esse movimento".

Tudo muda de figura assim que o método se apresenta em seus momentos como facetas concretas do desdobramento do ser na existência. Isto porque os três momentos estruturais gerados uniformemente, conforme a essência do existir explicada em diferentes níveis de sua revelação, já estão predelineados no chamado método fenomenológico. Não haverá surpresa se refletirmos que o método, como analítica existencial, explica a existência em sua essência. Fenômeno e Logos são duas partes integrantes da fenomenologia, a primeira das quais é, por sua vez, duplicada em si. Embora "fenômeno" seja "o que se manifesta em si próprio", o evidente e o verdadeiro, é também, ao mesmo tempo, "aquilo que de início e em geral não se manifesta". O velado, de onde o fenômeno tem de ser tirado à força e do qual se destaca, é momento essencial que lhe pertence. Isto se exprime no "des" de "des-velado", que é como Heidegger define o verdadeiro no sentido da palavra grega "Aletheia". $\mathrm{Na}$ analítica da existência reencontramos esses três momentos no projeto do ser esboçado, que se explicita como expressão (Logos) ou no fundamentar-se como privação excessiva ou na superabundância que se priva respectivamente, que se revela na sua continuidade como argumentação (Logos). Os três momentos juntos formam o caráter aberto da existência como sendo a verdade original e portanto a forma concreta do que significa fenomenologia no sentido de Heidegger radicalmente aprofundado se comparado com Husserl. E à medida que esse aprofundamento da análise vai progredindo, aprofunda-se também o conceito dessa triplicidade original que certamente no nível mais elevado, em "Zeit und Sein", também deveria 
ter sidc representado intimamente ligado à verdade do método ou então já o está, sem que isto seja conhecido.

Nos escritos ulteriores encontramos, ao invés disso, o "pensar essencial" exprimido como essa verdade, surge da recordação do ser em si. À medida que, através do método fenomenológico, o ser como ser da existência (temporabilidade) já tenha sido revelado em um nivel essencial, podemos encontrar no "pensar substancial" não "algo de novo", mas apenas um nível mais puro daquele método, desenvolvido por necessidade interior. Contudo só poderemos reconhecer o que realmente importa depois de termos considerado a ambigüidade intrínseca do método aprovado, primeiramente, como interpretação existencial-ontológica.

Do significado da definição "fenômeno" ficou evidente que o "não" é momento fundamental. Pelo fato de Heidegger entender, por princípio, as definições "negação" e "negar" à luz da lógica formal e de sua interpretação declaratória sempre que nos referirmos à sua filosofia, pretendemos fazer uso das expressões "não" (nich) e "negar" (nichten). O "des" do desvelado de um fenômeno apenas pode ser obtido em um negar. O fenômeno genuíno é descoberto no esboço do ser, que se consuma como pura referência com relação a verdade do ser no impulso de negação original, que encontra nessa verdade do ser seu ponto de referência. Heidegger fala do "vir a ser do esboço" como o "quê que possibilita o esboçado". Os esboços "trazem em si um vir-a-ser do qual se nutre igualmente a compreensão do ser". O vir-a-ser primário, porém, é o sentido ou a verdade do ser. Qualquer comportamento direto para com o ente é suportado por compreensão do ser, mesmo quando a princípio permanece geralmente oculto; todo esboçar, porém, possui em si o fundamento de sua possibilidade naquele vir-a-ser primário, que, como tal, não chega a se tornar temático. É preciso pois que o desocultado fenômeno esboçado se liberte de uma "negação" existente em obscuridade dupla: primeiro da "simulação" pelo ente, que se evidencia, mas que ao mesmo tempo absorve essa luz, de modo que não pode se destacar como tal em pureza; em segundo lugar da "recusa" de sua verdade reinante no ser como o próprio "vir-a-ser" primário. O rompimento através daquela simulação acontece na transcendência anuladora do ente simulante. Não este ente em si, porém o sentido do ser no qual a princípio se encontra é anulado na transcendência, para o fenômeno original que a princípio ainda está oculto em sua verdade. A transcendência sempre tem se realizado, pois de outra forma o ente-ser não poderia estar evidente, mas igualmente se perdeu no ente-ser e deve agora ser realizada explicitamente e em pureza. Fica claro então que simulação e negação são duas facetas de um mesmo acontecimento, pois no rompimento negante da simulação do "vir-a-ser" original, nasce o fenômeno descoberto. $O$ esboçar negante que se realiza a partir da pura relação para com a coisa e que é tudo menos um ato voluntário, livre, recebe do fenômeno prestes a se esboçar um contragolpe e se depara neces- 
sariamente recorrendo ao ente originariamente oculto e negado no seu sentido de ser, ao descobrir-se expressamente como momento do fenômeno esboçado: O negar está presente em si próprio e o desvelado obtém abrigo como seu momento enigmático.

Assim, pois, torna-se manifesto na analítica da existência que o ser humano, a princípio, se depara como existente entre o existente e se descobre e, por conseguinte, se interpreta em seu sentido de ser. Isto não representa uma infelicidade, mas sim uma necessidade da própria existência que precisa ser compreendida. Tal compreensão contudo só é possível a partir de motivo mais profundo, dentro de perspectiva mais abrangente do que a representada pela experiência em si, obtida no rompimento através da imagem dada e já consolidada do ser humano e do ser-ente que o envolve, ao esboçar o "estar-no-mundo". Secundariamente, porém, da verdade desse fenômeno o presente negado em sua presença, como presença, reedescobre na verdade só poder ser visualizado no esboço do "estar-no-mundo." Esse esboçar negante que, em si próprio, é reganhar do negado, vai evoluindo de nível para nível, retornando assim ao "vir-a-ser" original, como seu próprio fulcro, porém por força da eficácia dessa própria verdade de ser. A revelação deve evoluir gradativamente para realmente permanecer em relação autêntica à coisa. A negação não é absolutamente um negar exterior, mas sim recuperação onde a própria coisa se destaca de si mesmo em sua imediação. Heidegger fala de "libertação demonstrada", evidenciando nesse método afinidade profunda com a indução (epagoge) de Aristóteles. Em cada um dos níveis o fenômeno inicialmente esboçado é fundamentado mais espontaneamente por nova "situação hermenêutica" (campo de interpretação). O "estar-nomundo" conduz à "abertura", esta ao "cuidado", que por sua vez se revela como "decisão primordial" em sua "particularização" e "integralidade", como seu sentido de ser e assim como a verdade do ser da existência compreendida como "temporalidade". À luz de cada nível da revelação do fenômeno os precedentes não são decifrados, mas no seu sentido de ser somente mais visíveis espontaneamente e assim "repetidos". Em cada nível o oculto obscuro permanece igualmente eficaz no contra-ataque do negar, tornando novo avanço de esboçar negante não só necessário como possível. Assim lemos: "A libertação do ser original da existência deve-se-lhe arrancada na contrapartida contra a tendência interpretativa decadente onto-ontológica", "e conquistada contra a sua própria tendência de se ocultar".

Se analisarmos o mminho ou o método da revelação fenomenológica em sua negação presente, é preciso ainda acrescentar, como momento decisivo, que essa negação nasce do primeiro "vir-a-ser" como origem da qual o próprio pensamento, que assim se realiza, não dispõe. Está, ao contrário, entreque ao fenômeno que nasce do esboçar e tem de sentir essa presença em si próprio. Veremos o significado decisivo que isto tem para o caráter do logos dominante nessa fenomenologia. O método no pensamento heideggeriano não se modificou de forma 
alguma, apenas foi captado com maior acuidade e pureza. Assim exsurge a noção do sentido do refletir essencial: "Se deixarmos persistir a coisa em suas coisas do mundo cósmico, pensamos na coisa como coisa. Refletindo destarte nos deixamos influenciar pela essência cósmica da coisa. Pensando dessa forma somos atingidos pela coisa como coisa. Somos condicionados no sentido restrito da palavra. Deixamos a arrogância de tudo o que é incondicional para trás".

Torna-se evidente que a afirmação de Sartre, a censura de Bachelard dirigida contra a fenomenologia, de não observar suficientemente o que denomina de "coefficient d'adversité" dos objetos, atinge tanto a transcendência heideggeriana como a intencionalidade husserliana, mas não se aplica de forma alguma ao primeiro. Muito pelo contrário, seu pensamento é tão impregnado de tal "adversité" ou adversidade, que se chega a ver nela um motivo principal. O pensar essencial como pensamento do ser é pura convergência do método fenomenológico no sentido heideggeriano. Indubitavelmente nele se realiza uma mudança fundamentada na coisa. Na passagem da análise da existência ("Sein und Zeit") para a área da verdade do próprio ser ("Zeit und Sein") mostra-se em toda a diferença profunda a analogia evidente da passagem de fenomenologia do espírito para a lógica.

Relembrando mais uma vez o objetivo deste estudo, escapar rigorosamente de qualquer comparação externa de objetos heterogêneos, de enfocar, mediante comparação essencial a diferença real entre os dois sábios, para nos aproximarmos das grandes tarefas do futuro; uma comparação, todavia, que somente poderia se realizar através de penetração da interpretação hegeliana por Heidegger. A analítica da existência com relação ao método é análoga à fenomenologia do espírito e a revelação da verdade do ser à ciência da lógica, onde a tendência praticamente antagônica da passagem entre estas áreas não é facilmente compreensível.

Assim como Heidegger, Hegel apresenta em sua introdução a fenomenologia um "preconceito" de seu método, cuja apresentação real pertence à lógica ou, "melhor, é a própria lógica, pois o método é a estrutura do todo em sua essencialidade pura".

Assim como a "analítica", a "fenomenologia" desenvolve o método no exemplo concreto do espirito finito, ou seja, em sua cisão como consciência: "Na fenomenologia do espírito apresentei um exemplo desse método em um objeto concreto, na consciência" proclama Hegel. Contudo, não é por acaso que este exemplo se encontra no início, tampouco como o caminho para a verdade de Heidegger apenas incidentalmente se encaixa no ente humano citado na "existência", para o desenvolver no seu ser. Tanto a existência como a consciência representam ambas o ente no todo, já que em ambas o método já se encontra implícito, mas apenas implícito como caminho do ente no e em direção ao ser. No primeiro caso isto se evidencia na "compreensão pré-ontológica do ser" como um compreender que ainda não 
se delineia como compreensão do ser; no segundo caso como a experiência da passagem através e como as diferentes formas de consciência, que ainda não se conscientizou da necessidade enraizada na idéia ou, o que dá no mesmo, no método.

No desenvolvimento do método heideggeriano, portanto, alguns conceitos desempenham papel importante, os quais temos que considerar em primeiro lugar, já que são importantes para a comparação com o método hegeliano, visto que o próprio Heidegger apresenta esse método sob o ponto de vista de alguns desses conceitos. 